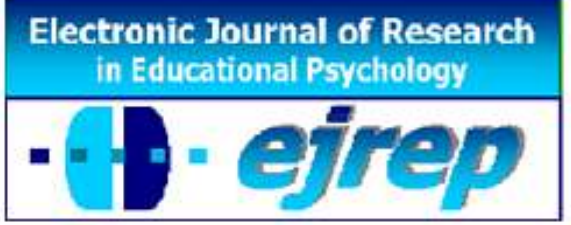

\title{
Assessments of intellectually gifted students with(out) characteristic(s) of ASD: An explorative evaluation among diagnosticians in various psycho-educational organisations
}

\section{Agnes E.J. Burger-Veltmeijer ${ }^{1}$, Alexander E.M.G. Minnaert ${ }^{2}$, Els J. van den Bosch ${ }^{3}$}

${ }^{1}$ Child Psychologist / Special Educationalist, Practice for psycho-educational assessment, ABV, Eindhoven

${ }^{1} \mathrm{PhD}$ researcher, Department of educational sciences, University of Groningen

${ }^{2}$ Professor, Department of educational sciences, University of Groningen

${ }^{3}$ Assistant Professor, Department of educational sciences,

University of Groningen

The Netherlands

Correspondence: Agnes E.J. Burger-Veltmeijer. ABV, Pasqualinistraat 8, 5622 AW Eindhoven, The Netherlands. E-mail: info@ agnesburger.nl, A.E.J.Burger-Veltmeijer@ rug.nl

(c) Education \& Psychology I+D+i and Ilustre Colegio Oficial de la Psicología de Andalucía Oriental (Spain) 


\begin{abstract}
Recently, Burger-Veltmeijer, Minnaert \& Van den Bosch (2014) constructed a conceptual framework, called the Strengths and Weaknesses Heuristic ( $\& \& W$ Heuristic) which might provide systematicity and coherence in research as well as psycho-educational praxis, regarding assessments of Intellectually Gifted (IG) students with (suspicion of) Autism Spectrum Disorders (ASD). In this contribution it was evaluated whether assessments in psychoeducational practice were consistent with the theoretical principles of the $S \& W$ Heuristic. The results indicated the possibility of missed signals of ASD-characteristics among IG-students as well as a trend that a rather large number of the assessments of IG students with(out) characteristics of ASD might not be arranged in a systematic dimensional needs-based way, according to the basic principles of the $S \& W$ Heuristic. These findings suggest either the necessity of optimisation of assessments trajectories in psycho-educational practice, or the necessity of optimisation of the $S \& W$ Heuristic itself.
\end{abstract}

Keywords: Needs-based assessment, Intellectual giftedness, ASD, Twice-exceptionality, Dimensional assessment

Received: 09/18/14 Initial acceptance: 10/18/14 Final acceptance: 03/01/15 


\section{Evaluación de alumnos de altas capacidades intelectuales con o sin característics de TEA: una exploración entre diagnosticadores de diversas organizaciones psicoeducativas}

Resumen

Recientemente Burger-Veltmeyer, Minnaert y Van der Bosch (2014) han desarrollado un marco conceptual denominado Heurístico de Fuerzas y Debilidades (Heurístico S\&W) para poder facilitar la sistematización y la coherencia en la investigación así como en la práctica psico-educativa, refiriéndose a pruebas de evaluación en estudiantes con Dotes de superdotación intelectual (I.G.) y con (sospecha de) Espectro de Trastorno Autista. En este aporte evaluaron si las pruebas de evaluación en la práctica psico-educativa resultaron consistentes con los principios teóricos del Heurístico S\&W. Los resultados mostraron la posibilidad de pérdidas de señales de ASD características en estudiantes IG así como una tendencia de que gran parte de las pruebas de evaluación en estudiantes IG con (o sin) características de ASD no se calificara de una manera sistemática, dimensional y basada en necesidades acorde con los principios básicos del Heurístico S\&W. Estas comprobaciones sugieren la necesidad de optimización de la ruta de pruebas de evaluación en la práctica psico-educativa o la necesidad de optimización del Heurístico S\&W en sí mismo.

Palabras Clave: necesidad específica de diagnosis, superdotación, autismo, doble excepcionalidad, diagnosis dimensional. 


\section{Introduction}

Up to recently, there was no theoretically grounded heuristic regarding assessments and interventions of children and youngsters (hereafter named 'students') with (suspicion of) Intellectual Giftedness and an Autism Spectrum Disorder (IG+ASD) (Assouline, Foley Nicpon \& Doobay, 2009; Burger-Veltmeijer, 2006a,b; Burger-Veltmeijer, Minnaert \& Van Houten-Van den Bosch, 2011; Huber, 2007). It was amply documented that this lack of theoretical grounding forced professionals to indicate psycho-educational assessment trajectories and interventions in a haphazard way, merely based on clinical opinions and anecdotal case reports (e.g. Barber, 1996; Burger-Veltmeijer, 2003; Cash, 1999; Donnelly \& Altman, 1994; Gallagher \& Gallagher, 2002; Grandin, 1992; Little, 2002; Neihart, 2000, 2009; Webb, Amend, Webb, Goerss, Beljan \& Richard Olenchak, 2005).

Recently, Burger-Veltmeijer, Minnaert \& Van den Bosch (2014) constructed a conceptual framework, called the Strengths and Weaknesses Heuristic (S\&W Heuristic) in order to tune assessment outcomes with intervention-indications in such a way that biased assessments could be reduced and that a grounded interconnection between assessment data and intervention-indications could be realised. The $S \& W$ Heuristic was meant to be an explorative point of departure in future empirical research, theory development and psycho-educational practical use. It is systematic and dynamic in nature, and serves as a frame of reference that provides coherence and new directions for research and psycho-educational praxis, and might eventually be applied to other categories of Twice-Exceptionality (TE) as well. This contribution provides a first attempt in the process of empirical validation of the $S \& W$ Heuristic, by means of a systematic qualitative evaluation among assessment dossiers of 36 Intellectually Gifted (IG) students.

\section{S\&W Heuristic}

The $S \& W$ Heuristic (Burger-Veltmeijer et al., 2014) has three fundamental and novel principles: 1 . The characteristics in Table 1 serve as dimensions that can be assessed in a comprehensive assessment. As such, assessment departs from IG+ASD characteristics (Burger-Veltmeijer et. al., 2011, 2014), instead of IG-characteristics apart from ASDcharacteristics, as seemed customary up till now (see for instance Assouline et al., 2009; Doobay, 2010); 2. Biased assessments can be reduced if assessments are primarily focused at 
the identification of S\&W profiles within the aforementioned dimensions, and subsequently, if still necessary, at the identification of categorical labels such as IG, ASD or IG+ASD. This is opposite to common psycho-educational practice, in which the label merely precedes and determines the intervention-indications. Moreover, it is opposite to DSM-5 related dimensional assessments, in which the categorical diagnosis precedes the dimensional severity level (APA, 2013; Dayle Jones, 2012; Widiger \& Samuel, 2005); and 3. Biased interventionindications can be reduced if the assessment outcomes, that is the individual identified S\&Ws, are translated per dimension into (Special) Psycho-Educational Needs (SPENS). This systematic dimensional connection between assessment-data and intervention-indications implies the existence of a grey zone (see Burger-Veltmeijer, 2006b, 2008) between 'normality' and 'exceptionality', and serves a Needs-Based Assessment (NBA, Pameijer, 2006) purpose.

Table 1

\begin{tabular}{|c|c|c|}
\hline & $\begin{array}{c}\text { Dimensions } \\
\text { (Burger-Veltmeijer et al., } 2\end{array}$ & \\
\hline Clusters & \multicolumn{2}{|c|}{ Characteristics of IG+ASD } \\
\hline \multirow[t]{7}{*}{ uneven development } & \multirow{5}{*}{$\begin{array}{l}\text { VIQ vs. PIQ vs. PSI } \\
\text { and other indexes, factors }\end{array}$} & FSIQ \\
\hline & & VIQ \\
\hline & & PIQ \\
\hline & & Index IQs, factor IQs \\
\hline & & PSI \\
\hline & \multirow{2}{*}{ cognitive vs. social and motor } & Social, see below \\
\hline & & motor \\
\hline \multirow[t]{2}{*}{ Academic achievement } & \multicolumn{2}{|l|}{ subject $\mathrm{x}$} \\
\hline & \multicolumn{2}{|l|}{ subject y (etc) } \\
\hline \multirow[t]{2}{*}{ superior nonverbal capacities } & \multicolumn{2}{|l|}{ math, physics, computer } \\
\hline & \multicolumn{2}{|c|}{ creative, divergent nonverbal thinking } \\
\hline \multirow[t]{2}{*}{ social issues } & \multicolumn{2}{|l|}{ social adjustment } \\
\hline & \multicolumn{2}{|c|}{ awareness of social rules and interactions } \\
\hline \multirow[t]{3}{*}{ Verbal-language issues } & \multicolumn{2}{|c|}{ precocious language development, } \\
\hline & \multicolumn{2}{|l|}{ verbal fluency } \\
\hline & \multicolumn{2}{|l|}{ Originality versus echolalia } \\
\hline \multirow[t]{2}{*}{ EF issues } & \multicolumn{2}{|c|}{ EF development: aspects or in general } \\
\hline & \multicolumn{2}{|c|}{ intense (obsessive) focus (for details), perfectionism } \\
\hline \multirow{2}{*}{$\begin{array}{l}\text { memory issues and central coherence } \\
(C C)\end{array}$} & \multicolumn{2}{|c|}{ CC development: aspects or in general } \\
\hline & \multicolumn{2}{|c|}{ excellent (rote) memory for factual info } \\
\hline hypersensitivity & \multicolumn{2}{|l|}{ general hypersensitivity } \\
\hline
\end{tabular}


In this section, we tried to explain the principles of the $S \& W$ Heuristic in a nutshell. This does no justice to its grounded construction and systematicity. Therefore we recommend interested readers to study the step by step explanation in the original publication (BurgerVeltmeijer et al., 2014).

\section{Purpose}

The objective of this study was the onset of the validation process of the $S \& W$ Heuristic. The purpose was to evaluate whether assessments in psycho-educational practice were consistent with the theoretical principles of the $S \& W$ Heuristic and whether there seemed to be any necessity of optimization of assessments trajectories in psycho-educational practice.

\section{Questions and inclusion criteria}

The central question of validation of the $S \& W$ Heuristic was: Do diagnosticians in various psycho-educational organisations, arrange assessment processes regarding students with (suspicion of) IG+ASD in a systematic dimensional needs-based way, conform the basic principles of the S\&W Heuristic? The concept 'students with (suspicion of) IG+ASD' could not literally be used as an inclusion criterion, however, because 'suspicion of' is multiinterpretable and the participating diagnosticians might select only the assessment dossiers of students of whom IG and ASD characteristics were detected or suspected before or in the intake stage of the assessment process. Since we were interested about obvious as well as possible camouflaged IG-, ASD-, and IG+ASD-characteristics in various stages of the assessment processes, and because we wanted to differentiate IG from HFA, as recommended by BurgerVeltmeijer et al (2014, p. 234), the inclusion was restricted to the following unambiguous criterion: Assessment dossiers in which the WISC-III-NL ${ }^{1}$ Full Scale IQ (FSIQ) was at least 130 (2 SDs above the mean), regardless of the initial reason for assessment request. On this ground, the leading question was: Do diagnosticians in various psycho-educational organisations, arrange assessment processes of IG students with(out) characteristics of ASD in a systematic unbiased dimensional needs-based way, in accordance with the basic principles of the S\&W Heuristic?

\footnotetext{
${ }^{1}$ Up to now, the WISC-III-NL is still the commonly used intelligence test for children, in (special) education and mental health care in The Netherlands. The WISC-IV was not adapted to the Dutch situation. The WISC-V will be translated and normed for the Dutch situation in the future.
} 


\section{Method}

\section{Participants}

The data were collected in a diversity of Dutch psycho-educational practices and institutions from our network (hereafter referred to as 'organisations'), situated in various parts of The Netherlands (north-east, middle, south-east and south-west), varying in terms of staff numbers and levels of expertise with Giftedness or ASD. A total of 36 assessment-dossiers in which the WISC-III-NL-FSIQ was at least 130, were analysed in seven organisations, among 19 diagnosticians. Two of the seven organisations were specialised in assessing and counselling students with (suspicion of) giftedness (hereafter named 'gifted expertise') and provided 14 of the 36 dossiers (39\%). Three of the seven organisations had general expertise in assessing and counselling students and had hardly any experience with giftedness (hereafter named 'general expertise') and provided 10 of the 36 dossiers (28\%). Two organisations had general expertise in assessing and counselling students, including experience with giftedness (hereafter named 'both expertises') and provided 12 of the 36 dossiers (33\%). In the 36 dossiers, $81 \%$ of the assessed students were boys, $19 \%$ were girls. Ages ranged from 6-14 years (M=8.39). The mean Full-Scale IQ was 138.22. Grades ranged from 1-9. All assessments were carried out in the years 2009-2013 (86\% in 2011 and 2012) and performed or supervised by qualified diagnosticians, with a post-master degree.

\section{Procedure and instruments}

Every dossier was thoroughly examined by a qualified diagnostician, being a child and youth psychologist with post-master qualifications, who was specialised in giftedness as well as learning and developmental disorders as well as Twice Exceptionalities (TE). The dossiers included all available anamnestic ${ }^{2}$ documents (e.g. forms filled out by parents, teachers or referrers, letters and documents from parents, teachers or relevant others) as well as test protocols, interview and observation transcriptions, assessment reports, letters et cetera.

\footnotetext{
${ }^{2}$ Here, anamnestic refers to medical as well as psycho-educational and socio-economic case history.
} 
Relevant text passages were anonymously transcribed in a table of variables and subsequently translated to quantitative scores according to a codebook. As far as relevant for this contribution, the criteria of translations from qualitative into quantitative data are included in the subsequent paragraph of Results.

\section{Design and data analysis}

The analysis took place by means of the following subquestions: 1 . How many dossiers show the principle of systematic dimensional assessment of the $S \& W$ Heuristic among the stages of the assessment process? 2. How many assessments with a Needs Based Assessment (NBA) purpose, show the principle of systematic dimensional assessment of the $S \& W$ Heuristic. 3. Are any ASD characteristics present in any stage of the assessment process? 4. Is the principle of systematic dimensional assessment of the $S \& W$ Heuristic present in case of ASD characteristics?

Most results were analysed in a descriptive way, by means of frequencies and distributions. Percentages in frequency tables have been rounded off to integers, unless otherwise stated. Dependencies between some variables were analysed by means of cross tabulations. Because of the rather small sample size, Fisher's Exact Test was used to test significances of dependencies. In cross tabulations, less than $80 \%$ of the cells were valued more than 5 . Consequently, significant differences were not interpreted in an exact way, but were considered to indicate trend.

\section{Results}

Stages in assessment process

Pameijer (2006) distinguished five stages in Needs-based Assessment (NBA). In line with the S\&W Heuristic, we renamed three of them, and added a sixth stage.

The intake-stage includes anamnestic data, gathered from parents, students, and possibly teachers, counsellors, paediatricians et cetera. It was analysed whether these data were present in the dossier, and if so, whether or not the initial question(s) of parents and possibly teachers or others were included. Initial questions are wishes and expectations regarding the assessment, such as 'is my child gifted?', 'what is the matter with this child?', 'does this student needs counselling?', 'how can we help', 'should this child skip a grade?', 'what are the 
(special) educational needs of this student?'. The intake-stage was present in all 36 dossiers. In 5 dossiers (14\%) no information on any initial questions was included. Four of these came from one organisation.

The strategy-stage includes the justification of the assessment strategy by the generation of alternative hypotheses and the translation of these into investigation questions (Pameijer, 2006, p. 14). Investigation questions guide the assessment. In the $S \& W$ Heuristic the emphasis does not lie on the strategy-stage. Burger-Veltmeijer et al. (2014, p. 232) discuss, however, that bias may be inherent in various stages of an NBA procedure, for instance in the selection of dimensions and instruments used in the assessment. Such selections take place in the strategy-stage. Therefore, we regard the strategy-stage as an essential part of a systematic dimensional assessment process. It was analysed whether a plan of action was made after the intake-stage and, if so, whether or not the intake information and/or the initial questions of parents and/or teachers and/or relevant others were translated into hypotheses and/or investigation questions. If the dossier had a plan of action including such translation, the strategystage was valued as 'fully present'. If the dossier included a plan of action without such translation, the strategy-stage was valued as 'seemingly present'. We expected the strategy-stage to be 'fully present' in every dossier. It turned out, however, that the strategy-stage was 'fully present' in 17 out of 36 dossiers (47\%) and 'seemingly present' in 19 out of 36 dossiers $(53 \%)$.

The investigation-stage (called stage of 'diagnosis' by Pameijer, 2006) includes assessment data, gathered from testing, observation, interviews and/or questionnaires. We expected the investigation-stage to be present in all 36 dossiers, which proved to be the case.

The indication-stage (called stage of 'needs assessment' by Pameijer, 2006) includes the translation of assessment data into indications for interventions (intervention-indications). In the $S \& W$ Heuristic it is emphasized that the S\&Ws should be translated per dimension into Special Psycho-Educational Needs (SPENs) (Burger-Veltmeijer et al., 2014). It was analysed whether such translations were present in the dossiers, either explicitly described in terms of needs, or rather implicitly described in terms of an integral discussion or in terms of recommendations. Moreover, it was analysed whether or not the translations were based on a rather unbiased analysis, as recommended in the $\mathrm{S} \& \mathrm{~W}$ Heuristic. Unbiased means that the translation was based on an analysis of both the Ss as well as the Ws (as far as these were assessed 
in the investigation-stage) without neglecting the consideration of either one. Biased means that the translation was mainly based on either Ss or Ws with ignorance of the consideration of either one, or with rather one-sided interpretations. For example, the characteristic 'weak information processing' being unilaterally interpreted as being a motivational problem stemming from underachievement and the intellectual giftedness, without considering or explaining why it should not be interpreted as a possible neuropsychological deficit. Or vice versa, the interpretation of concentration problems as an 'attention regulation deficit' without considering motivational problems in line with the high IQ. Information on the indication-stage could be analysed in 34 dossiers. In line with the principles of the $S \& W$ Heuristic, we expected the absence of biased translations in the indication stage. It turned out, however, that in 25 out of 34 dossiers $(74 \%)$ the translations in the indication-stage were assembled in an unbiased way, and in 9 out of 34 dossiers $(26 \%)$ the translations were assembled in a rather biased way, all in favour of Ss.

The advice-stage (called stage of 'recommendations' by Pameijer, 2006) includes the advised interventions. In the $S \& W$ Heuristic, the integration of all SPENs, including contradictory ones, may help to create the eventual advised interventions (Burger-Veltmeijer, 2014, p.229). We expected the advice-stage to be present in all of the 36 dossiers. This was confirmed.

The evaluation-stage was not mentioned by Pameijer (2006), but in the $S \& W$ Heuristic, it is an important connection between the needs-based and possible classification-based phases in assessments (Burger-Veltmeijer et. al., 2014, p229). This stage contains information on how or when the effects of the advised interventions should be evaluated. In line with the S\&W Heuristic, we expected the evaluation-stage to be present in all dossiers. It turned out, however, that an evaluation-stage was present in only 8 out of 36 dossiers (22\%).

\section{Assessment purposes}

It was analysed whether the purpose of the assessment was classification-based, needsbased, both or neither one. We defined an assessment as classification-based if it was explicitly mentioned or implicitly substantiated in the strategy-stage that the assessment was aimed at the exclusion or confirmation of any categories or labels such as 'giftedness', 'underachievement', 'ASD', 'dyslexia', et cetera. Needs-based was defined if it was explicitly mentioned or implicitly substantiated in the strategy-stage, that the assessment was aimed at the 
identification of psycho-educational needs and/or intervention-indications. If an assessment purpose became not clear in the strategy stage, it was derived from the initial questions in the intake stage in combination with the decisions (classification-based, needs-based or neither one) in the indication-stage. It turned out that in 26 out of 36 dossiers (72\%) the assessments were needs-based or both classification-based plus needs-based and in 10 out of 36 dossiers $(28 \%)$ the assessments were classification-based.

It would be in line with the principles of the $\mathrm{S} \& \mathrm{~W}$ Heuristic regarding an unbiased and systematic dimensional assessment process, if all dossiers with 'needs-based' or 'both' purposes would show a translation of intake data into investigation questions in the strategy stage and that this percentage would be higher than that of dossiers with a 'classification-based' purpose.

Cross tabulation of the variables 'assessment purpose' and 'strategy-stage' could be calculated on all 36 dossiers. Contrary to the aforementioned expectations crosstabs revealed that only in 9 out of the 26 dossiers (35\%) with the purpose 'needs-based' or 'both', this 'translation' was scored 'fully present', whereas 8 out of 10 dossiers $(80 \%)$ with a 'classificationbased' purpose scored 'fully present' in the strategy stage. Fisher's Exact Test indicated significant differences in these percentages, $\chi^{2}(1, N=36)=5.97, p=.018$. Because $25 \%$ of the cells in the crosstab have an expected count less than 5 , this significance should not be interpreted in an exact way, but should be considered a trend.

It would also be in line with the principles of the $\mathrm{S} \& \mathrm{~W}$ Heuristic regarding unbiased and dimensional assessment, if all dossiers with 'needs-based' or 'both' purposes, would show an unbiased translation of assessment-data into intervention-indications in the indication-stage.

Cross tabulation of the variables 'assessment purpose' and 'indication-stage' could be analysed for 34 dossiers. It was revealed that in 17 out of the 25 dossiers $(68 \%)$ with the purpose 'needs-based' or 'both', this 'translation' was scored unbiased. Moreover, we expected this percentage to be higher than that of dossiers with a 'classification-based' purpose. Contrary to this expectation, however, the percentage of unbiased translations among dossiers with a classification purpose, was higher (8 out of 9, 89\%). Fisher's Exact Test indicated this difference in percentages to be insignificant, $\chi^{2}(1, N=34)=1.48, p=.39$. 


\section{ASD characteristics}

The dossiers were examined for the presence of any behavioural characteristics that are associated with ASD, in current and/or past behaviour. The behavioural characteristics were clustered into four categories, selected and combined on the basis of descriptions from the Diagnostic and Statistical Manual of mental disorders, fourth edition (DSM-IV) ${ }^{3}$ as well as literature on autism and ASD (e.g. Vermeulen, 2002; Volkmar, Lord, Bailey, Schultz \& Klin, 2004; Wing, 1992). Per cluster, examples of behaviours were selected from the Autism Diagnostic Observation Schedule ADOS (Lord, Rutter, Dilavore \& Risi, 2009) as well as the Dutch adaptation of the ADOS-2 (Bildt, Greaves-Lord \& De Jonge, 2013), and the Autism Diagnostic Interview - Revised ADI-R (Rutter, Le Couteur \& Lord, 2003). The four clusters were:

Inadequate reciprocal social interactions, such as: inadequate eye contact or facial expressions, little empathy, little understanding of consequences of their own behaviour to others, having few friends, little connection with other children, inadequate social advances, contacts are usually problematic, regularly involved in fights or being bullied, inappropriate behaviour, being able to understand social situations but being unable to apply this knowledge to daily living situations. Or, in general, referred to as social development not being in accordance with age.

Language and communication insufficiently attuned to social communication, such as: immediate or delayed echolalia, (e.g. formal or pedantic language, speaking solemnly), stereotypical or typical use of words or phrases, not or inadequately giving or asking for (personal) information, no or inadequate reciprocal sequences, overly egocentric speech patterns, no or inadequate use of (spontaneous) gestures to support social communication.

Shortage of fantasy and imagination, such as: Absence of imagination or fantasy in play or (verbal and / or nonverbal) communication, lack of creativity in thought and action.

\footnotetext{
3 The dossier analysis was done in 2012/2013. At that time, the Diagnostic and Statistical Manual of mental disorders, fifth edition (DSM-5) (APA, 2013) was not yet available in The Netherlands. After publication of the DSM-5 (APA, 2013, 2014) it turned out that ASD is identified by means of the two categories 'Deficits in social communication and social interaction' and 'Restricted repetitive patterns of behaviour', which are included in the four ASD-clusters.
} 
Stereotyped and restricted behaviours or interests, such as: unusual sensory interests (e.g. smelling and groping objects), unusual or repetitive hand and finger movements, selfinjurious behaviour, coercion and rituals, restricted patterns of interest, obsession with certain topics, rigid thinking.

It was analysed per cluster whether or not any characteristic was present in the intakestage, the investigation-stage and/or the indication-stage in the dossiers, regardless of how the parents, relevant others or the diagnostician were interpreting the behaviour in question. If one or more behavioural characteristics were mentioned, the relevant cluster was valued 'present'. If one or more of the behavioural characteristics was mentioned as not being the case, or if the opposite behaviour was mentioned to be the case, the relevant cluster was valued 'not present'. If none of the behavioural characteristics of a cluster were mentioned, neither as 'present' nor as 'not present', the corresponding cluster was valued 'ignored'.

In line with the research questions, we were interested in the presence of any ASD characteristics, as well as whether or not the assessments were performed in line with the systematic dimensional viewpoint of the $S \& W$ Heuristic. Assessments are supposed to be in line with the dimensional viewpoint of the $S \& W$ Heuristic, if clusters that were present in the intake stage received conscious attention in the investigation-stage, that is, either in a confirming way as being 'present', or in a denying way as being 'not present'. If a given characteristic was present in the intake-stage and not mentioned at all, that is 'ignored', in the investigation-stage, the assessment was not supposed to be in line with the dimensional viewpoint of the $S \& W$ Heuristic for the relevant ASD-cluster.

The same reasoning applies to the continuous dimensional line between investigationstage and indication-stage of the assessment. That is, if any ASD-cluster that was mentioned in the investigation-stage was 'ignored' in the indication-stage, then the assessment was supposed to be not in accordance with the systematic dimensional viewpoint of the $S \& W$ Heuristic for the relevant cluster.

Inadequate reciprocal social interactions: In the cross-tabulation of the intake-stage with the investigation-stage, information on 'inadequate reciprocal social interactions' could be analysed among 34 dossiers. It was revealed that in the intake-stage, characteristics of this cluster were 'present' in 22 out of 34 dossiers (65\%), 'not present' in 10 out of 34 dossiers 
(29\%) and 'ignored' in only 2 out of the 34 dossiers (6\%). This means that in the intake-stage conscious attention was paid to at least one aspect of inadequate social reciprocal communication in $94 \%$ of the dossiers. We expected that of the 22 dossiers that scored 'present' in the intake-stage, none scored 'ignored' in the investigation-stage. It turned out, however, that 6 of the 22 dossiers (27\%) scored 'ignored' in the investigation stage. This means that $27 \%$ of the assessments were not in line with the dimensional viewpoint of the $S \& W$ Heuristic for this ASD-cluster of inadequate reciprocal social interactions.

In the cross-tabulation of the investigation-stage with the indication-stage, information on 'inadequate reciprocal social interactions' could be analysed among 33 dossiers. It was revealed that in the investigation-stage, characteristics of this cluster were 'present' in 11 out of 33 dossiers (33\%), 'not present' in 12 out of 33 dossiers (36\%) and 'ignored' in 10 out of $33(30 \%)$. This means that in the investigation-stage conscious attention was paid to at least one aspect of inadequate social reciprocal communication in 23 out of 33 dossiers (70\%). Furthermore, of the 11 dossiers that scored 'present' in the investigation-stage, 7 dossiers scored 'present', 2 dossiers scored 'not present' and 2 dossiers scored 'ignored' in the indication-stage. This means that 2 out of 11 dossiers (18\%) were not in line with the dimensional viewpoint of the $S \& W$ Heuristic for this dimension of inadequate reciprocal social interactions.

Insufficiently attuned Language and communication: In the intake-stage, characteristics of the ASD cluster Insufficiently attuned Language and communication could be analysed in 35 dossiers and scored 'present' in 1 out of 35 dossiers (3\%), 'not present' in 5 out of 35 dossiers (14\%) and 'ignored' in 29 out of 35 dossiers (83\%). In the investigation-stage, characteristics of this cluster could be analysed in 34 dossiers and scored 'present' in 1 out of 34 dossiers (3\%), 'not present' in 6 out of 34 dossiers (18\%) and 'ignored' in 27 out of 34 dossiers $(79 \%)$.

In this ASD-cluster, the percentages of 'ignorance' are rather high, which means that rather little conscious attention was paid to this ASD-cluster in the intake-stage and the investigation-stage. Hence cross tabulations, such as in case of the previous ASD-cluster of Inadequate reciprocal social interaction, were not calculated. The same applies to the following two ASD-clusters. 
Shortage of fantasy and imagination: In the intake-stage, characteristics of the ASD cluster Shortage of fantasy and imagination could be analysed in 35 dossiers and scored 'present' in 2 out of 35 dossiers (6\%), 'not present' in 10 out of 35 dossiers (29\%) and 'ignored' in 23 out of 35 dossiers (66\%). In the investigation-stage, characteristics of this cluster could be analysed in 34 dossiers and scored 'present' in none of the 34 dossiers ( $0 \%)$, 'not present' in 6 out of 34 dossiers (18\%) and 'ignored' in 28 out of 34 dossiers (82\%).

Stereotyped and restricted behaviours: In the intake-stage, characteristics of the ASD cluster Stereotyped and restricted behaviours could be analysed in 35 dossiers and scored 'present' in 5 out of 35 dossiers (14\%), 'not present' in 5 out of 35 dossiers (14\%) and 'ignored' in 25 out of 35 dossiers (71\%). In the investigation-stage, characteristics of this cluster could be analysed in 34 dossiers and scored 'present' in 1 out of 34 dossiers (3\%), 'not present' in 6 out of 34 dossiers (18\%) and 'ignored' in 27 out of 34 dossiers (79\%).

\section{Summary}

Assessment stages: The following assessment-stages were distinguished: intake-stage, strategy-stage, investigation-stage, indication-stage, advice-stage and evaluation-stage. All stages except the evaluation-stage were present in almost all dossiers. Information about the evaluation stage, which is an important connection between the needs-based and possible classification-based stages in the $S \& W$ Heuristic, was only found in $22 \%$ of the dossiers. In many dossiers (53\%), intake-data including initial questions were not systematically translated into hypotheses and/or investigation questions. This means that the assessment strategy might start in a biased way. Moreover, in a rather large part (26\%) of the dossiers, investigation-data were not systematically translated into intervention-indications, that is, the translations were assembled in a rather biased way in favour of Ss.

Assessment purpose: In only $35 \%$ of the dossiers with the purpose 'needs-based' or 'both', intake-data including initial questions were systematically translated into hypotheses and/or investigation questions. In $68 \%$ of the dossiers with the purpose 'needs-based' or 'both', investigation-data were systematically translated into intervention-indications. This means that a rather large number of assessments of IG students with(out) characteristics of ASD with at least a needs-based purpose might not be arranged in a systematic dimensional needs-based way, according to the basic principles of the S\&W Heuristic. Moreover, and con- 
trary to our expectations, assessments with a classification-based purpose showed more systematic translations in the strategy-stage than assessments with at least a needs-based purpose. As to systematic translations in the indication-phase there seemed to be no large difference between needs-based and classification-based purposes.

ASD-clusters: Of the four ASD clusters, only behaviours from the domain Inadequate reciprocal social interactions were mentioned rather often, especially in the intake-stage and the investigation-stage, either as being present or as not being the case, which means that rather often conscious attention is paid to this ASD-cluster. The ASD-cluster inadequate reciprocal social interactions was scored 'present' in about $65 \%$ of the dossiers in the intakestage. We assumed that the presence of any characteristic out of any ASD-cluster should alert diagnosticians on the possibility of characteristics out of other ASD-clusters. Therefore, and in line with the idea of the $S \& W$ Heuristic regarding reduction of biased assessments, one might expect these other ASD-clusters to receive conscious attention, that is scored 'present' or 'not present', in about $65 \%$ of the assessments as well. In other words, we expected the other three ASD-clusters to score 'ignored' in about $35 \%$ or less in the intake-stage and in the investigation-stage. It turned out, however, that the ignorance of characteristics out of the other three ASD-clusters scored much higher (66\%-83\% in the intake-stage, $79 \%-82 \%$ in the investigation-stage).

\section{Conclusion and discussion}

Burger-Veltmeijer, Minnaert \& Van den Bosch (2014) constructed a conceptual framework, called the Strengths and Weaknesses Heuristic ( $S \& W$ Heuristic) which might provide systematicity and coherence in research as well as psycho-educational praxis, regarding assessments of Intellectually Gifted (IG) students with (suspicion of) Autism Spectrum Disorders (ASD). The objective of the present study was to evaluate whether psychoeducational assessments of IG-students with(out) characteristics of ASD are consistent with the theoretical principles of the $S \& W$ Heuristic. It turned out that in the intake-stage and investigation-stage, characteristics out of the ASD-cluster Inadequate reciprocal social interactions were present rather often and received conscious attention in almost all dossiers. This is according to the principle of unbiased assessment of the $S \& W$ heuristic, especially since 'social issues' is one of its basic dimensions (see Table 1). The continuous line of this dimension was ignored, however, in a rather large amount of dossiers, which is not in accordance with 
the systematic dimensional principles of the $S \& W$ heuristic. Moreover, a rather large amount of the dossiers revealed the absence of systematic continuous translations of data from intakestage into investigation-stage into indication-stage, especially in dossiers with at least a needsbased purpose. Furthermore, the absence of paying conscious attention to the other three ASD-clusters, in case of presence of the cluster Inadequate reciprocal social interactions, indicates the possibility of missed signals of ASD-characteristics among IG-students.

All of this indicates a trend that a rather large number of the assessments of IG students with(out) characteristics of ASD might not be arranged in a systematic dimensional need-based way, according to the basic principles of the $S \& W$ Heuristic. These findings suggest either the necessity of optimisation of the $S \& W$ Heuristic itself, or the necessity of optimisation of assessments trajectories in psycho-educational practice. In the latter case the $S \& W$ Heuristic, which makes implicit knowledge explicit, might prevent the amount of gaps in needs-based assessment processes, and thus might meet a need.

\section{Limitations}

Because of the relatively small sample size and because the organisations were not randomly selected, the conclusions are nothing more than the indication of small trends which need further exploration. Nevertheless, they can be considered as a first step in the validation process of the principles of the $S \& W$ Heuristic.

Despite the fact that we defined each variable as clearly as possible, it was sometimes hard to score them. It was sometimes not obvious, for instance, whether a particular characteristic belonged to the intake-stage or investigation-stage, or whether a characteristic should be considered as a fact or as an interpretation, due to the differences between diagnosticians in describing their data and forming their dossiers.

The ASD-clusters were scored as present, if one or more of its behavioural characteristics were present in the dossier. This means that dossiers with the same score on an ASDcluster may differ in the number of behavioural characteristics and their impact on the situation of the student. Therefore, further in-depth research is highly recommended. 


\section{Future research}

Future research should focus on the central issue whether the $S \& W$ Heuristic has the right to exist as such or whether adjustments are needed in theory and/or in practice. To this end, further in-depth research could be performed by means of comparative case descriptions and might focus on various categories of questions. Accordingly, questions regarding the principle of systematic dimensionality among the assessment stages, regarding studentcharacteristics, and regarding differences between organisations with different expertises could be brought to the fore. Hence, the S\&W Heuristic might be adapted when necessary, or practice should be changed in line with the heuristic. 


\section{References}

APA (2000). Diagnostic and statistical manual of mental disorders, fourth edition, text revision. $\left(D S M-I V-T R^{\circledR}\right)$. Washington, DC: American Psychiatric Association.

APA (2013). Diagnostic and statistical manual of mental disorders, fifth edition, (DSM-5).

Washington, DC: American Psychiatric Association.

APA (2014). Handboek voor de classificatie van psychische stoornissen (DSM-5).

Nederlandse vertaling van Diagnostic and statistical manual of mental disorders, fifth

Edition. [Manual for the classification of mental disorders (DSM-5). Dutch translation of the diagnostic and statistical manual of mental disorders, fifth Edition]. Amsterdam, Netherlands: Boom.

Assouline, S.G., Foley Nicpon, M. \& Doobay, A. (2009). Profoundly gifted girls and autism spectrum disorder: A psychometric case study comparison. Gifted Child Quarterly, 53(2), 89-105. doi: 10.1177/0016986208330565.

Barber, C. (1996). The integration of a very able pupil with Asperger Syndrome into a mainstream school. British Journal of Special Education, 23(1), 19-24.

Bianco, M., Carothers, D.E. \& Smiley, L.R. (2009). Gifted students with Asperger syndrome: Strategies for strength-based programming. Intervention in School and Clinic, 44(4), 206-215. doi: 10.1177/1053451208328827.

Bildt, A., Greaves-Lord, K. \& De Jonge, M. (2013). ADOS-2 Nederlandse bewerking. [ADOS-2 Dutch Adaptation]. Amsterdam, Netherlands: Hogreve uitgevers.

Burger-Veltmeijer, A.E.J. (2003). Asperger en Hoogbegaafd: Implicaties voor Ouders.

[Asperger's and Highly Gifted: Implications for parents]. Talent, 5(1), 13-15.

Burger-Veltmeijer, A.E.J. (2006a). Hoogbegaafdheid plus autismespectrumstoornissen

(HB+ASS): een verwarrende combinatie (1) [Giftedness plus autism spectrum disorders (IG+ASD): a confusing combination (1)]. Tijdschrift voor Orthopedagogiek, 45(6), 276286.

Burger-Veltmeijer, A.E.J. (2006b). Hoogbegaafdheid plus autismespectrumstoornissen (HB+ASS): een verwarrende combinatie (2) [Giftedness plus autism spectrum disorders (IG+ASD): a confusing combination (2)]. Tijdschrift voor Orthopedagogiek, 45(9), 414424.

Burger-Veltmeijer, A.E.J., Minnaert, A.E.M.G., Van Houten-Van den Bosch, E.J. (2011). 
The co-occurrence of intellectual giftedness and autism spectrum disorders: A literature review. Educational Research Review, 6(1), 67-88. doi:10.1016/j.edurev.2010.10.001. Burger-Veltmeijer, A.E.J., Minnaert, A.E.M.G., Van den Bosch, E.J. (2014). Needs-based assessment of students with (suspicion of) intellectual giftedness and/or an autism spectrum disorder: Design of a heuristic. Electronic Journal of Research in Educational Psychology, 12(1), 211-240. doi: 10.14204/ejrep.32.13119.

Cash, A.B. (1999). A Profile of Gifted Individuals with Autism: The Twice-Exceptional Learner. Roeper Review, 22(1), 22-27. doi: 10.1080/02783199909553993.

Dayle Jones, K., (2012). Dimensional and cross-cutting assessments in the DSM-5. Journal of Counseling \& Development, 90(4), 481-487. doi: 10.1002/j.1556-6676.2012.00059.x

Donnelly, J.A., Altman, R. (1994). The autistic savant: Recognizing and serving the gifted student with autism. Roeper Review, 16(4), 252-256. doi: 10.1080/02783199409553591.

Doobay, A. F. (2010). Comparison of cognitive, psychosocial, and adaptive behaviour profiles among gifted children with and without autism spectrum disorder. US, University of Iowa (dissertation).

Foley Nicpon, Allmon, A., Sieck, B. \& Stinson, R.D. (2011a). Empirical investigation of twice-exceptionality: Where have we been and where are we going? Gifted Child Quarterly, 55(1), 3-17. doi: 10.1177/0016986210382575.

Gallagher, S.A. \& Gallagher, J.J. (2002). Giftedness and Asperger's syndrome: A new agenda for education. Understanding Our Gifted, 14(2), 7-12.

Grandin, T. (1992). An inside view of autism. In E. Schopler \& B.B. Mesibov (Eds.), Highfunctioning individuals with autism (pp. 105-126). New York/London: Plenum Press

Huber, D.H. (2007). Clinical presentation of autism spectrum disorders in intellectually gifted students. Iowa, US: University of Iowa (dissertation).

Little, C. (2002). Which is it? Asperger's syndrome or giftedness? Defining the difference. Gifted Child Today Magazine. Januari 01.

Lord, C., Rutter, M., Dilavore, P., Risi, S. (2009). Autism Diagnostic Observation Schedule; ADOS manual. Los Angeles, CA: Western Psychological Services.

Lord, C., Rutter, M., Dilavore, P., Risi, S., Gotham, K., Bishop, S. (2012). Autism Diagnostic Observation Schedule, Second Edition (ADOS-2, Modules 1-4). Torrance, CA: Western Psychological Services.

Neihart, M. (2000). Gifted Children with Asperger's Syndrome. Gifted Child Quarterly, 44(4), 222-230. doi: 10.1177/001698620004400403. 
Neihart, M. (2009). Gifted children with autism spectrum disorders. Waco, TX: Prufrock Press.

Pameijer, N. (2006). Towards needs-based assessment: Bridging the gap between assessment and practice. Educational and Child Psychology, 23(3), 12-24.

Rutter, M., Le Couteur, A., Lord, C. (2003). Autism Diagnostic Interview-Revised (ADI-R) Manual. Los Angeles, CA: Western Psychological Services.

Vermeulen, P. (2002). Beter vroeg dan laat en beter laat dan nooit: De onderkenning van autisme bij normaal tot hoogbegaafde personen. [Better early than late and better late than never: The recognition of autism in intellectually normal to gifted individuals]. Berchem, Belgium: EPO.

Volkmar, F.R., Lord, C., Bailey, A., Schultz, R.T. \& Klin, A. (2004). Autism and pervasive developmental disorders. Journal of Child Psychology and Psychiatry, 45(1), 135-170. doi: 10.1046/j.0021-9630.2003.00317.x.

Webb, J.T., Amend, E.R., Webb, N.E., Goerss, J., Beljan, P. \& Richard Olenchak, F. (2005). Misdiagnosis and dual diagnoses of gifted children and adults. Scottsdale: Great Potential Press.

Widiger, T.A., \& Samuel, D.B. (2005). Diagnostic categories or dimensions? A question for the Diagnostic and Statistical Manual of Mental Disorders-Fifth Edition. Journal of Abnormal Psychology, 114, 494-504. doi: 10.1037/0021-843X.114.4.494. 
Agnes E.J. Burger-Veltmeijer et al.

[This page intentionally left blank] 